NASA Technical Memorandum 105400

\title{
Brush Seal Leakage Performance With Gaseous Working Fluids at Static and Low Rotor Speed Conditions
}

Julie A. Carlile, Robert C. Hendricks, and Dennis A. Yoder

Lewis Research Center

Cleveland, Ohio

Prepared for the

37th International Gas Turbine and Aeroengine Congress and Exposition sponsored by the American Society of Mechancial Engineers

Cologne, Germany, June 1-4, 1992 


\section{BRUSH SEAL LEAKAGE PERFORMANCE WITH GASEOUS WORKING FLUIDS}

\section{AT STATIC AND LOW ROTOR SPEED CONDITIONS}

Julie A. Carlile, Robert C. Hendricks, Dennis A. Yoder

National Aeronautics and Space Administration

Lewis Research Center

Cleveland, Ohio 44135

\section{ABSTRACT}

The leakage performance of a brush seal with gaseous working fluids at static and low rotor speed conditions was investigated. This report includes the leakage results for air, helium, and carbon dioxide at several bristle/rotor interferences. In addition, the effects of packing a lubricant into the bristles and also of reversing the pressure drop across the seal were investigated. Results were compared to that of an annular seal at similar operating conditions. In order to generalize the results, they were correlated using corresponding state theory. The brush seal tested had a bore diameter of $3.792 \mathrm{~cm}(1.4930 \mathrm{in}$.$) , a fence height of 0.0635 \mathrm{~cm}(0.025 \mathrm{in}$.$) , and$ 1800 bristles/cm-circumference ( 4500 bristles/in.-circumference). Various bristle/rotor radial interferences were achieved by using a tapered rotor.

The brush seal reduced the leakage in comparison to the annular seal, up to 9.5 times. Reversing the pressure drop across the brush seal produced leakage rates approximately the same as that of the annular seal. Addition of a lubricant reduced the leakage by 2.5 times when compared to a non-lubricated brush seal. The air and carbon dioxide data were successfully correlated using corresponding state theory. However, the helium data followed a different curve than the air and carbon dioxide data.

\section{NOMENCLATURE}

$\begin{array}{ll}a_{1} \ldots a_{5} & \text { constants } \\ b_{1} \ldots b_{4} & \text { constants } \\ C_{f} & \text { flow coefficient } \\ f & \begin{array}{l}\text { ratio of fluid- } \alpha \text { temperature to fluid-o } \\ \text { temperature }\end{array} \\ G & \text { mass flow rate } \\ G^{*} & \text { mass flow rate based on critical properties } \\ g & \text { Gibb's free energy } \\ \text { h } & \text { ratio of fluid- } \alpha \text { volume to fluid-o volume } \\ \text { P } & \text { pressure }\end{array}$

$\mathrm{R} \quad$ universal gas constant

T temperature

$\mathrm{V}$ volume

Z compressibility

$\rho$ density

$\omega \quad$ acentric factor

Subscripts

c critical constant

in inlet

- property of known fluid

r reduced parameter

$\alpha \quad$ property of fluid to be predicted

$\phi \quad$ correction factor

$\theta \quad$ correction factor

\section{INTRODUCTION}

A brush seal is a compliant seal and, as seen in Fig. 1, consists of a bristle pack held between two washers. The bristles have an initial radial interference with the rotor and are angled $30^{\circ}$ to $60^{\circ}$ from the radial centerline. This arrangement allows the seal to easily adapt to thermal effects, machining tolerances, and shaft excursions. In order for conventional seals (such as labyrinth and annular seals) to meet the same adaptability requirements, they require a clearance between the rotor and seal. Thus, brush seals have the potential to significantly reduce the leakage over conventional seals.

The back washer is designed as an annular seal so that it is as close to the rotor as possible while still accommodating shaft excursions and growth due to thermal and centrifugal effects. Since brush seals are a contacting seal, bristle material and rotor coating become a major design consideration. Because of this, the bristles are made 


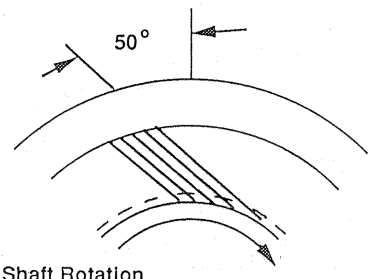

Shaft Rotation

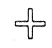

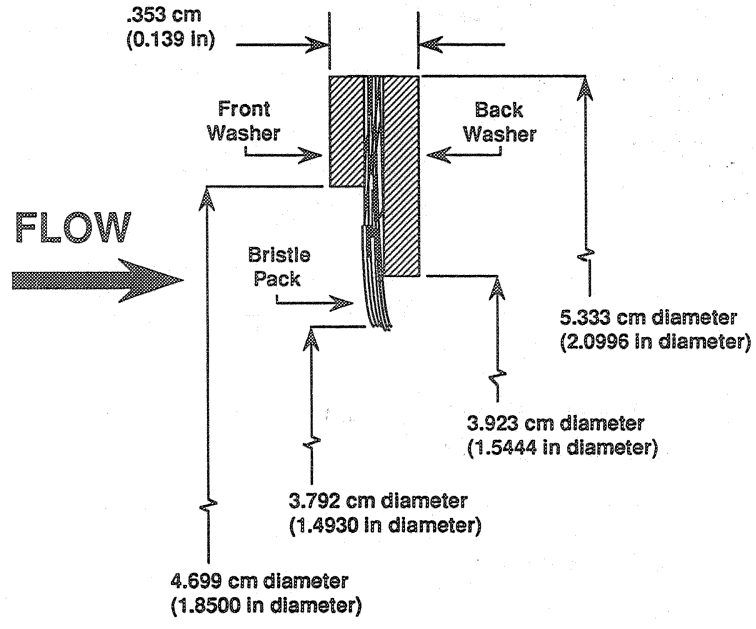

Figure 1.-Brush seal geometry.

of a superalloy (e.g., Haynes 25 and Hastelloy X), and the rotor is coated with a highly polished ceramic such as $\mathrm{ZrO}_{2}$ or $\mathrm{CrC}$.

Brush seals are currently being considered for such applications as gas turbine engines, turbopumps, gas compressors, and steam generators. Previous work demonstrates that brush seals reduce leakage from one-third to one-fourth that of four and five cavity labyrinth seals (Flower, 1990, and Gorelov et al., 1988). Ferguson (1988) found the leakage to be $1 / 10$ to $1 / 20$ that of labyrinth seals running in the same turbomachine with clearances of $0.75 \mathrm{~mm}$. In addition, brush seals have been found by Childs (1990) to enhance rotor stability compared to labyrinth seals. For these investigations, air was used for the working fluid, and little information exist in the open literature for other working fluids. For this paper, the performance of a brush seal using gaseous air, carbon dioxide, and helium for the test fluids is presented.

Several analytical models for brush seals have been developed. A bulk flow model has been developed by Braun, et. al. (1990) and Hendricks, et. al (1991a). Chupp, et. al. (1991) developed a model which generalizes the results over a range of conditions using the effective thickness of the bristle pack. The model is especially effective in accounting for fluid thermal effects at high pressure ratios. For this paper, the results are correlated using corresponding state theory. This method produces a single curve; which is a function of the brush seal geometry; from which the leakage performance can be predicted for any fluid at any state.

Several other considerations were investigated for this report. The effect of reversing the pressure drop across the brush seal was studied for application to cases where the brush seal is installed improperly or reverse flow occurs during adverse engine operation. In addition, the effect of putting a lubricant into the brush seal pack was examined.
Data for gaseous air, helium, and carbon dioxide are presented for static and dynamic rotor conditions. Air data are given for bristle/rotor radial interferences of 0.0018 and $0.0061 \mathrm{~cm}(0.0007$ and 0.0024 in.). Helium data are given for bristle/rotor radial interferences of 0.0033 and $0.0061 \mathrm{~cm}$ (0.0013 and 0.0024 in.). Carbon dioxide data are given for a bristle/rotor radial interference of $0.0061 \mathrm{~cm}(0.0024 \mathrm{in}$.). Results of correlating the data using corresponding states theory are presented. For comparison purposes, an annular seal was tested in air and helium, and the results were compared to that of the brush seal. In addition, results of the seal packed with a lubricant and also of a seal tested with the pressure drop reversed are presented.

\section{SEAL ASSEMBLY}

A bench-scale apparatus shown in Fig. 2 was used for this investigation. The apparatus consisted of a pressure vessel, rotor, and seal. The pressure vessel held the seal in position and acted as a circumferential seal on the outside diameter. There were two openings for the working fluid to enter near the base of the vessel located $180^{\circ}$ apart. A halogen light was placed in the bottom of the pressure vessel for alignment purposes and to act as a back light for visualization of the bristle/rotor dynamics.

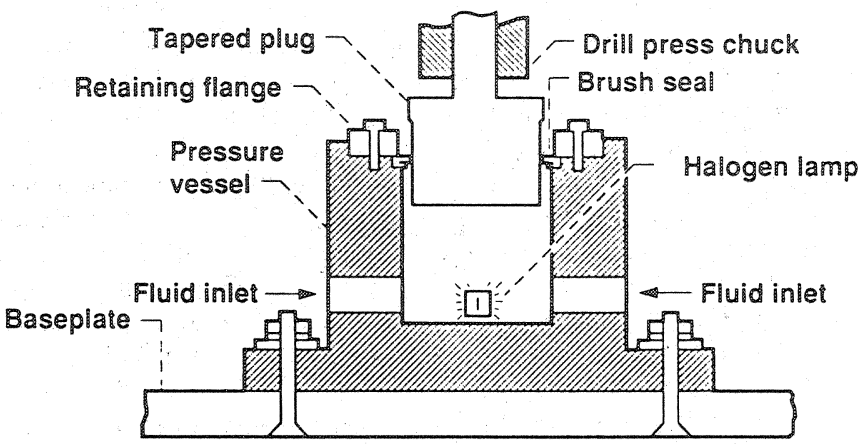

Eigure 2.-Schematic of test apparatus.

The 304 stainless steel rotor shown in Fig. 3 was driven by a drill press. It was tapered so that the bristle/rotor interference could be changed by adjusting the vertical height. The taper ranged from 38.6 to $37.8 \mathrm{~mm}$ ( 1.5202 to $1.4877 \mathrm{in}$.) in diameter over $25.36 \mathrm{~mm}$ ( $0.9986 \mathrm{in}$.). Since the seals axial lengths were small, the taper did not effect the leakage.

\section{SEAL DESIGN}

Both a brush seal and an annular seal were tested for comparison purposes. The geometry of the brush seal is given in Table $\mathbb{I}$ and is shown in Fig. 1. The brush seal was $0.353 \mathrm{~cm}$ (0.139 in.) thick and had a bore diameter of $3.792 \mathrm{~cm}(1.4930 \mathrm{in}$.). The outside diameter was $5.333 \mathrm{~cm}$ (2.0996 in.). The inside diameters of the front and back washers were 4.699 and $3.923 \mathrm{~cm}$ (1.8500 and 1.5444 in.), respectively. Thus, the fence height (i.e., the radial free

\section{TABLE I.-BRUSH SEAL SYSTEM SPECIFICATION}

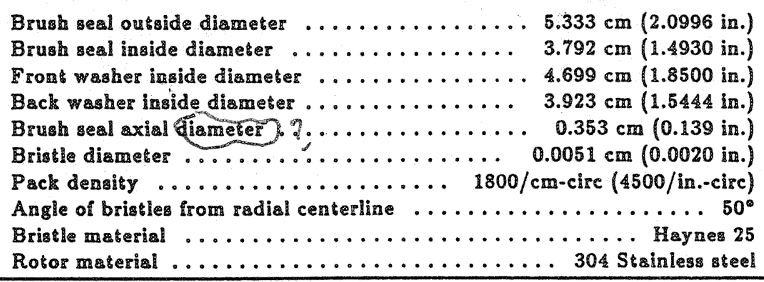



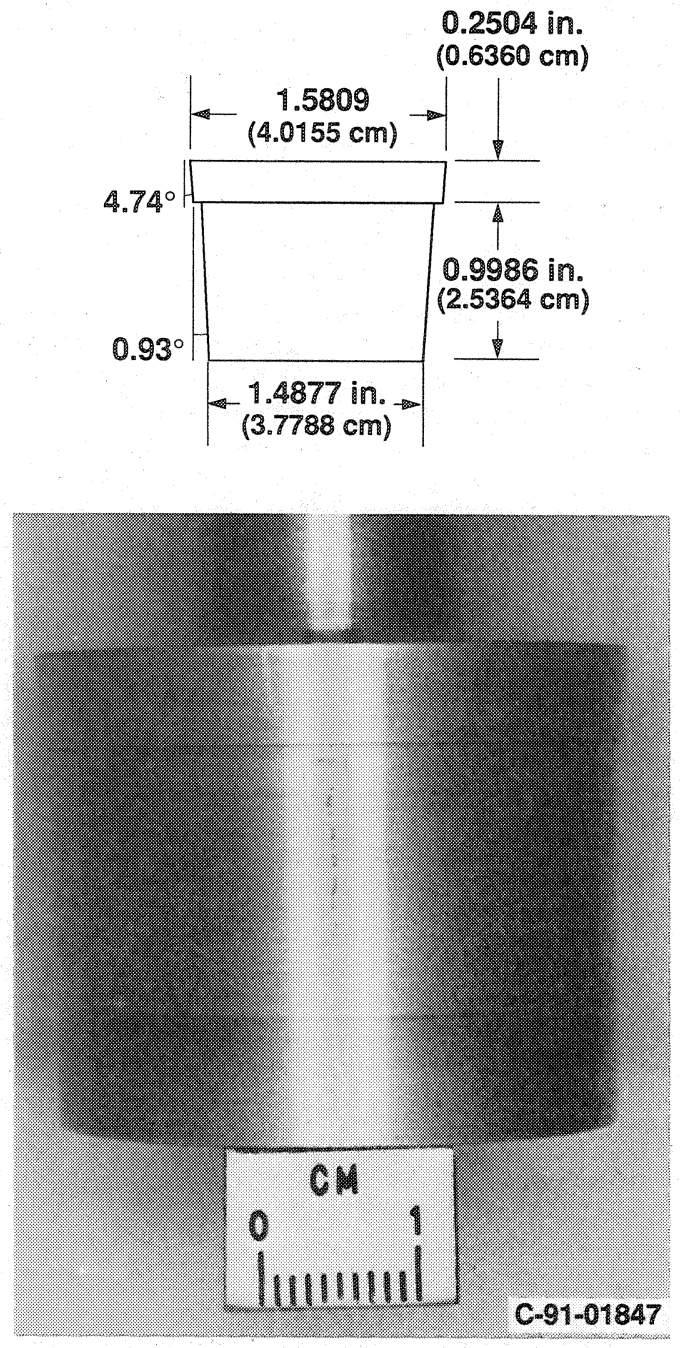

Figure 3.-Photo and schematic of the tapered rotor.

length of the extension of the bristles beyond the back washer) was $0.0635 \mathrm{~cm}(0.025 \mathrm{in}$.). The bristles were made of Haynes 25 and angled $50^{\circ}$ from the radial centerline. The bristles were $0.0051 \mathrm{~cm}$ (0.002 in.) in diameter and had a packing density of $1800 / \mathrm{cm}$-circumference ( 4500 bristles/in.-circumference).

For comparison purposes, the annular seal was designed to have the same axial length as the brush seal, $0.353 \mathrm{~cm}(0.139 \mathrm{in}$.). It had an inside diameter of $3.8610 \mathrm{~cm}$ (1.5200 in.) which is equal to the diameter at the top of the rotor taper. Again, by changing the height of the rotor the clearance could be changed and a range of leakages could be determined.

\section{TEST FACILITY}

A flow schematic of the system including instrumentation is shown in Schlumberger, et. al., 1991. Based on the flow rate, one of three parallel flow lines; each having a calibrated venturi meter; was used. The test fluid temperature and pressure were measured near the inlet to the pressure vessel (line losses were approximately 6 percent of the inlet pressure). The exit pressure was assumed to be equal to the measured ambient pressure. All temperatures were measured using type $\mathrm{E}(\mathrm{Cu} / \mathrm{Ni})$ thermocouples and pressures by strain-gage pressure transducers.

\section{TEST CONFIGURATIONS}

The test configurations are summarized in Table II. Data were first taken for the brush seal at a bristle/rotor radial interference of $0.0061 \mathrm{~cm}(0.0024 \mathrm{in}$.) with gaseous air, helium, and carbon dioxide for the test fluids. Additional data were taken at radial interferences of 0.0018 and $0.0033 \mathrm{~cm}(0.0007$ and $0.0013 \mathrm{in}$.) for air and helium, respectively.

\begin{tabular}{|c|c|c|c|}
\hline $\begin{array}{l}\text { Configurstion } \\
\text { radial clearance } \\
\end{array}$ & Air & Helium & $\begin{array}{l}\text { Carbon } \\
\text { dioxide }\end{array}$ \\
\hline \multicolumn{4}{|l|}{ Brash } \\
\hline$-0.0061 \mathrm{~cm}(-0.0024 \mathrm{im})$. & $x$ & $x$ & $x$ \\
\hline$-0.0018 \mathrm{~cm}(-0.0007 \mathrm{im})$. & $x$ & $\cdot$ & \\
\hline$-0.0033 \mathrm{~cm}(-0.0013 \mathrm{in})$. & & $\mathrm{x}$ & \\
\hline \multicolumn{4}{|l|}{ Brasele mal revered } \\
\hline$-0.0053 \cos (-0.0021 \mathrm{ins})$ & $x$ & & \\
\hline \multicolumn{4}{|l|}{ Brasia al lebricated } \\
\hline$-0.0061 \mathrm{~cm}(\cdot 0.0024 \mathrm{in})$ & $x$ & & \\
\hline \multicolumn{4}{|l|}{ Aramalas seal } \\
\hline $0.0053 \mathrm{~cm}(0.0021 \mathrm{in})$. & $\mathrm{x}$ & & \\
\hline $0.0178 \mathrm{~cm}(0.0070 \mathrm{in})$. & $x$ & & \\
\hline $0.0302 \mathrm{~cm}(0.0119 \mathrm{in})$. & & $x$ & \\
\hline
\end{tabular}

Next, the brush seal was inverted so that the pressure'drop would be applied in the reverse direction. This configuration had a radial interference of $0.0053 \mathrm{~cm}(0.0021 \mathrm{in}$. $)$ and was tested with air. Due to the direction of the bristle angle with the rotor, only data with a static rotor was taken.

A lubricant (halocarbon grease) was put into the bristle pack and along the inside diameter. This configuration was tested with air as the working fluid and a radial interference of $0.0061 \mathrm{~cm}$ (0.0024 in.).

Lastly, an annular seal was tested for comparison purposes. For air, it was tested at radial clearances of 0.0053 and $0.0178 \mathrm{~cm}$ $(0.0021$ and $0.0070 \mathrm{in}$.). For helium, it was tested at a radial clearance of $0.0302 \mathrm{~cm}(0.0119 \mathrm{in}$.). These clearances were selected in order to obtain the leakage rates over a feasible working range.

Before each run, the pressure transducers were calibrated, and the system purged. A hand valve was opened to allow the working fluid to enter the pressure vessel, flow through the seal, and exit to ambient. Data were taken as the pressure was increased and then decreased to determine hysteresis effects. This procedure was repeated for static and dynamic rotor conditions. For the dynamic condition, the shaft rotation was $400 \mathrm{rpm}$. The gases were at ambient temperature [285- $295 \mathrm{~K}(513-531 \mathrm{R})]$.

\section{CORRESPONDING STATES}

An analysis was performed to generalize the various working fluid data using corresponding state theory. The extended van der Wsals theory of corresponding states had been verified for several fluids and fluid mixtures by Mollerup (1978) and applied to two-phase choked flow by Hendricks and Simoneau (1973 and 1977).

The premise of corresponding states is that all thermodynamic surfaces can be mapped to a single surface when expanded about the 
thermodynamic critical point. Thus, the properties of a fluid $(\alpha)$ can be predicted using another fluid $(O)$ when the proper mapping is used. Equation (1) and (2) give the mapping for compressibility and Gibb's free energy, respectively (Hendricks and Sengers, 1979).

$$
\begin{gathered}
\mathbb{Z}_{\alpha}(\mathrm{V}, \mathrm{T})=\mathbb{Z}_{0}(\mathrm{~V} / \mathrm{h}, \mathrm{T} / \mathrm{f}) \\
\mathrm{g}_{\alpha}(\mathrm{V}, \mathrm{T})=\mathrm{g}_{0}(\mathrm{~V} / \mathrm{h}, \mathrm{T} / \mathrm{f})-\mathrm{RT} \operatorname{In}(\mathrm{h})
\end{gathered}
$$

where,

$$
\begin{aligned}
& \mathrm{h}=\left[\mathrm{V}_{\alpha \mathrm{c}} / \mathrm{V}_{\mathrm{oc}}\right] \phi \\
& \mathfrak{f}=\left[\mathrm{T}_{\alpha c} / \mathrm{T}_{o c}\right] \theta \\
& \phi=1+\left(\omega_{\alpha}-\omega_{0}\right)\left[\mathrm{b}_{1}\left(\mathrm{~V}_{\mathrm{r}}-\mathrm{b}_{2}-\mathrm{b}_{3}\left(\mathrm{~V}_{\mathrm{r}}-\mathrm{b}_{4}\right) \ln \mathrm{T}_{\mathrm{r}}\right]\right. \\
& \theta=1+\left(\omega_{\alpha}-\omega_{0}\right)\left[\mathrm{a}_{1}-\mathrm{a}_{2} \operatorname{In} \mathrm{T}_{\mathrm{r}}+\left(\mathrm{a}_{3}-\mathrm{a}_{4} / \mathrm{T}_{\mathrm{r}}\right)\left(\mathrm{V}_{\mathrm{r}}-\mathrm{a}_{5}\right)\right]
\end{aligned}
$$

Values for $a_{1} \ldots a_{5}, b_{1} \ldots b_{5}, \phi$ and $\theta$ can be found in McCarty (1977).

From this, it can be seen that for mass flow substitution into the conventional Bernoulli equation gives Eq. 3,

$$
G_{\alpha}=C_{f_{c}} \frac{\sqrt{\Delta P / V}}{\sqrt{\left(h^{2} / f\right)\left(Z_{o} / Z_{\alpha}\right) c}}
$$

For simple gases flowing through a venturi, over large ranges in fluid states removed from the thermodynamic critical point, flow rates can be normalized by equation 4 (Hendricks, 1977).

$$
\text { G. } \sqrt{T_{r} / P_{r}}=C_{\hat{f}} / 5.0
$$

where,

$$
\begin{aligned}
\mathrm{G}_{\mathrm{r}} & =\mathrm{G} / \mathrm{G}^{*} \\
\mathrm{G}^{*} & =\frac{\sqrt{\mathrm{P}_{\mathrm{c}} \rho_{\mathrm{c}}}}{\sqrt{\mathrm{Z}_{\mathrm{c}}}} \\
\mathrm{T}_{\mathrm{r}} & =\mathrm{T} / \mathrm{T}_{\mathrm{c}} \\
\mathrm{P}_{\mathrm{r}} & =\mathrm{P} / \mathrm{P}_{\mathrm{c}}
\end{aligned}
$$

The critical constants for air, helium, and carbon dioxide are given in Table III.

TABLE III.-CRITICAL CONSTANTS (GASP)

\begin{tabular}{|l|c|c|c|c|c|}
\hline Fluid & $\begin{array}{c}T_{c} \\
(K)\end{array}$ & $\begin{array}{c}P_{c} \\
\left(M P_{Q}\right)\end{array}$ & $\begin{array}{c}\rho_{c} \\
(\mathrm{~g} / \mathrm{cc})\end{array}$ & $Z_{c}$ & $\begin{array}{c}G^{2} \\
\left(\mathrm{~g} / \mathrm{cm}^{2} \mathrm{~s}\right)\end{array}$ \\
\hline $\mathrm{Air}$ & 132.55 & 3.766 & 0.313 & 0.3162 & 6106 \\
\hline $\mathrm{He}$ & 5.19 & 0.227 & 0.0693 & 0.3039 & 720 \\
\hline $\mathrm{CO}_{2}$ & 304.21 & 7.3835 & 0.464 & 0.2769 & 11123 \\
\hline
\end{tabular}

It should be noted that for low molecular weight fluids like hydrogen, helium, and neon at low temperatures quantum effects play an important role, and the corresponding state correlations require reduction parameters (Gunn, et. al. 1966). For this report, the temperature was high and quantum effects were neglected.

In summary, the normalized parameters stated evolved from the solution of one dimensional conservation equations. The maximum mass flux is related to curvature of the thermodynamic surface, $\mathrm{dV} / \mathrm{dP}$ (Eq. 3). Corresponding states relations are strictly valid for only isentropic losses. Thus, the maximum mass flux maps only for isentropic flows and is nearly valid at the throat where $\mathrm{dV} / \mathrm{dP}$ is much larger than nonisentropic losses. In a practical sense, the relations are valid to within a constant over a large range in thermodynamic states and flow geometries. Thus, if a single data point is found to establish this constant (which relates the working fluid and geometry), flow can be reliably predicted. For a fixed geometry, it appears that the nonisentropic losses for choked flows could be related to the thermodynamic surface, and the viscosity is correctable in terms of the extended theory of corresponding states. In addition, the direct solution of the conservation equations with an accurate equation of state does not require the use of the specific heat ratio (mass flux is proportional to the change in enthalpy).

\section{RESULTS AND DISCUSSION}

The objectives of this investigation were: (1) to determine the performance of brush seals at several bristle/rotor interferences with various working fluids and to compare the results to an annular seal; (2) to generalize the results using corresponding state theory; (3) to determine the effect of packing lubricant into the bristles; and (4) to determine the effect of reversing the pressure drop across the seal.

Figure 4 presents the performance data of gaseous air, helium, and carbon dioxide at a bristle/rotor radial interference of $0.0061 \mathrm{~cm}$ (0.0024 in.). Figure $4(\mathrm{a})$ gives a plot of volumetric flow rate versus pressure drop across the seal for the various gases at static and dynamic $(400 \mathrm{rpm})$ shaft conditions. All volumetric flow rates presented in this report are at standard temperature and pressure. For the carbon dioxide and air data, there was a slight decrease in leakage with shaft rotation; however, this effect was small ( 8 percent). Hysteresis effects were negligible. For the air and carbon dioxide data, the flattening at high pressure is not realistic and requires investigation. This is also the case in Fig. 7.

Figure 4(b) gives a plot of $G_{r} \sqrt{T_{r}}$ versus $\operatorname{Pr}$ for the gaseous air and carbon dioxide data; where $\mathrm{T}_{\mathrm{r}}=\mathrm{T}_{\mathrm{in}} / \mathrm{T}_{\mathrm{c}}, \mathrm{G}_{\mathrm{r}}=\mathrm{G} / \mathrm{G}^{*}, \mathrm{P}_{\mathrm{r}}=$ $\mathrm{P}_{\text {in }} / \mathrm{P}_{\mathrm{c}}$. Since the flow area was not known, it was taken to be a constant and set equal to $1.0 \mathrm{~cm}^{2}$. The data fell onto a linear fit such that the slope $=G_{r} \sqrt{T_{r}} / P_{r}=0.0169$ and 0.0155 for the static and dynamic shaft conditions, respectively. Figure $4(\mathrm{c})$ is the same plot with the helium data added. It can be seen that the helium data followed a different curve than that of the carbon dioxide and air data. An improvement in correlating the helium data with the air and carbon dioxide data can be seen if $G_{r} \sqrt{T}$ is plotted against $P_{r}=\Delta P / P_{c}$ as shown in Fig. $4(d)$. However, the helium data still follows a slightly different curve than that of the air and carbon dioxide data. The cause for this requires further investigation.

Figure 5 presents the results of the annular seal compared to the brush seal for gaseous air and helium for static and dynamic (400 rpm) shaft conditions. Figure $5(\mathrm{a})$ shows a plot of volumetric flow rate versus pressure drop for the brush and annular seals with helium as the working fluid. The radial clearances for the brush and annular seal were $-0.0061 \mathrm{~cm}(-0.0024 \mathrm{in}$.) and $0.0302 \mathrm{~cm}$ (0.0119 in.), respectively. The annular seal leakage rate was 9.5 times greater than that of the brush seal. 


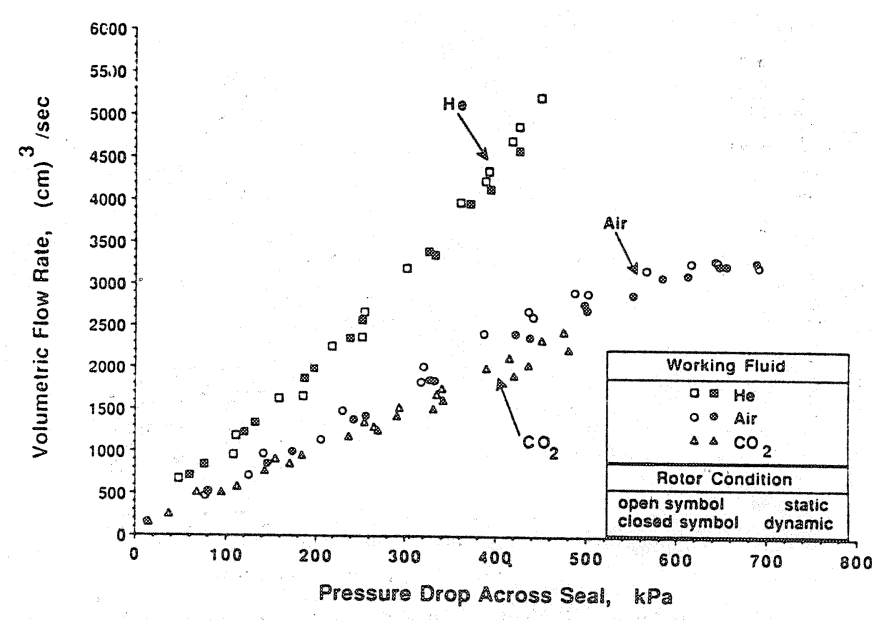

(a) Volumetric flow rate versus pressure drop across the brush seal for Helium, Air, and Carbon Dioxide.

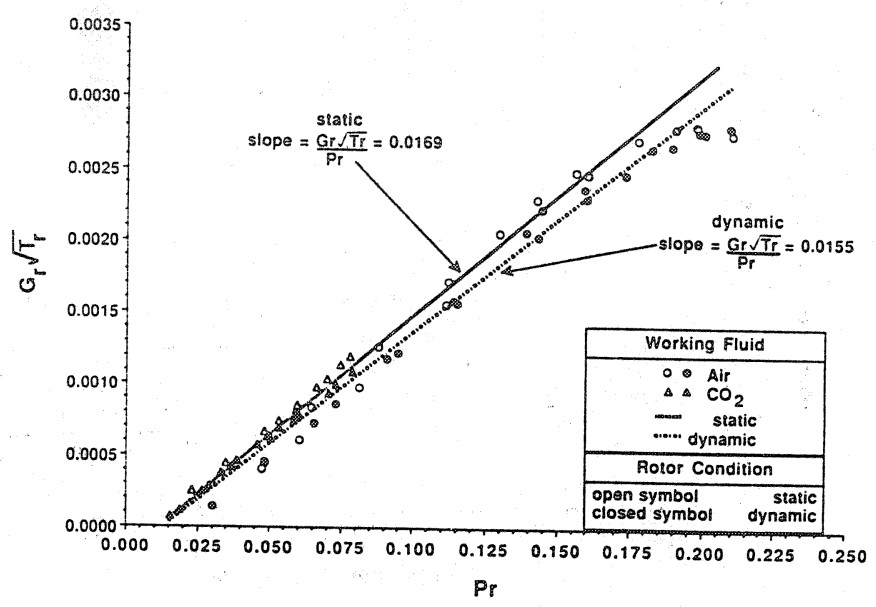

(b) $G_{r} \sqrt{T_{r}}$ versus $P r$, where $P_{p}=\frac{P_{\text {in }}}{P_{c}}$, for Air and
Carbon Dioxide.

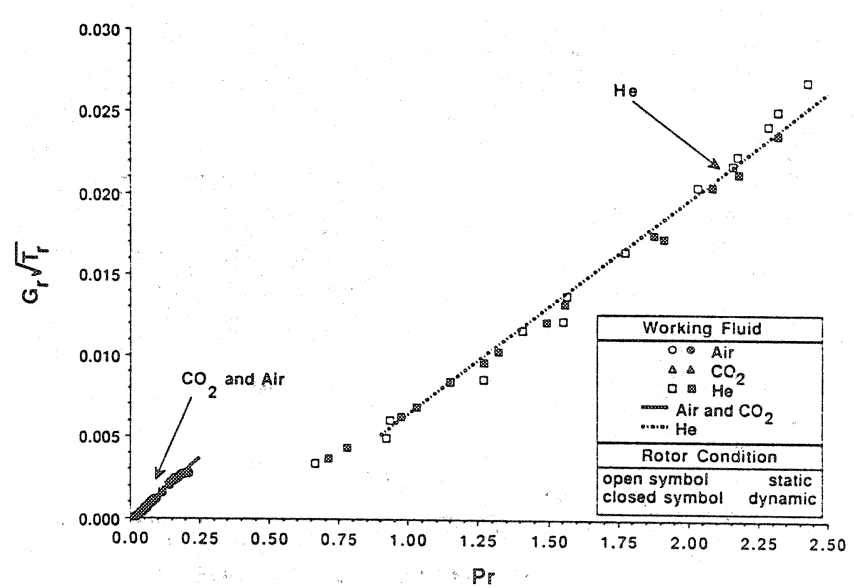

(c) $G_{r} \sqrt{T_{r}}$ versus $P r$, where $P_{r}=\frac{P_{\text {in }}}{P_{c}}$, for Air, Carbon
Dioxide, and Helium.

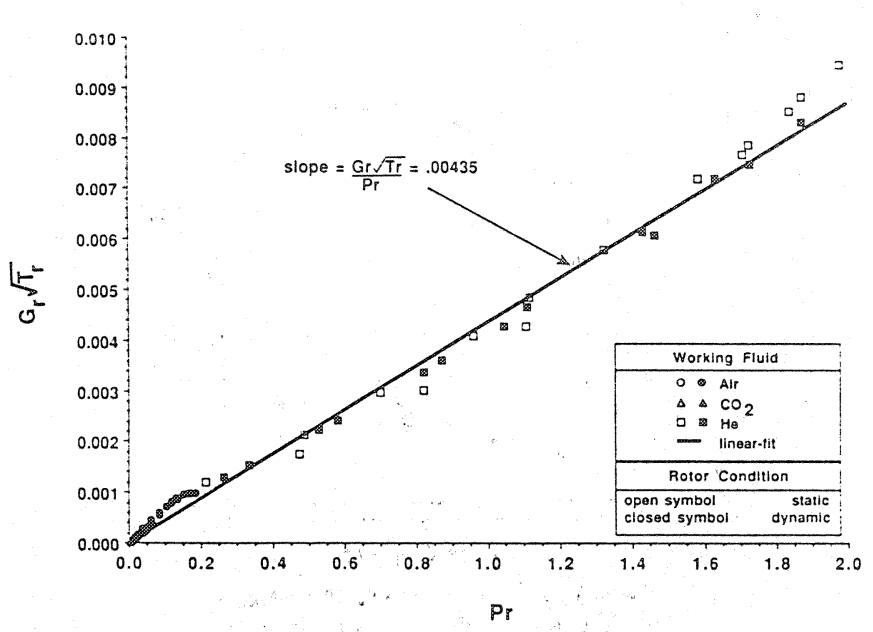

(d) $G_{r} \sqrt{T_{r}}$ versus $P r$, where $P_{r}=\frac{\Delta P}{P_{c}}$, for Air, Carbon
Dioxide, and Helium.

Figure 4.-Brush seal performance at static and dynamic rotor conditions and a bristle/rotor radial interference of $+0.0061 \mathrm{~cm}$ $(+0.0024$ in.) for Air, Helium, andCarbon Dioxide.

Figure 5(b) shows a plot of volumetric flow rate versus pressure drop for the brush and annular seals with air as the test fluid for static and dynamic $(400 \mathrm{rpm})$ shaft conditions. In addition, the plot includes the data for the brush seal with the pressure drop across the brush reversed. The radial interference for the brush was $0.0061 \mathrm{~cm}$ (0.0024 in.). Two radial clearances were tested for the annular seal; 0.0053 and $0.0178 \mathrm{~cm}(0.0021$ and $0.0070 \mathrm{in}$.). For the brush seal with the pressure drop applied in the reverse direction the seal had a radial interference of $0.0053 \mathrm{~cm}(0.0021$ in.). Over this range of radial clearances, the annular seal leakage rate was between 3.5 and 7.5 times greater than the brush seal. The brush seal with the pressure drop applied in the reverse direction leaked 6.5 times that of the normal brush seal. With the pressure drop across the seal reversed giving the bristles no surface to press against, the reversed brush seal leaked approximately the same amount as that of the annular seal.

Figure 6 presents the results for the lubricated seal with air as the test fluid compared to the nonlubricated brush seal static and dynamic ( $400 \mathrm{rpm}$ ) shaft conditions. It gives a plot of volumetric flow rate versus pressure drop across the seal at a radial interference of $0.0061 \mathrm{~cm}(0.0024 \mathrm{in}$.). For the static condition, the lubricated seal reduced the leakage 2.5 times that of the nonlubricated seal. For the dynamic condition, the lubricated seal reduced the leakage 1.5 times that of the nonlubricated seal. The lubricant served to hold the bristles in place and to block the porosity through the bristle pack. The static condition showed improvement over the dynamic case. This is the result of the lubricant acting as a seal at the bristle/rotor interface for the static case. This behavior can be seen in the steam data found in Schlumberger, et. al. (1991). The steam changed phases as it passed through the seal from vapor to liquid. The liquid became entrained in the bristles and blocked the fluid flow in the same manner as the lubricant.

Figure 7 presents the effect of bristle/rotor interference on leakage. Figure $7(\mathrm{a})$ gives a plot of volumetric flow rate versus pressure drop across the brush for helium at bristle/rotor radial interferences of 0.0033 and $0.0061 \mathrm{~cm}(0.0013$ and $0.0024 \mathrm{in}$.). Figure 7(b) gives a plot of volumetric flow rate versus pressure drop across the brush for air at bristle/rotor radial interferences of 0.0018 and $0.0061 \mathrm{~cm}(0.0007$ and $0.0024 \mathrm{in}$.). Both static and dynamic data are presented. As expected, the flow rate decreased with an increased interference. 


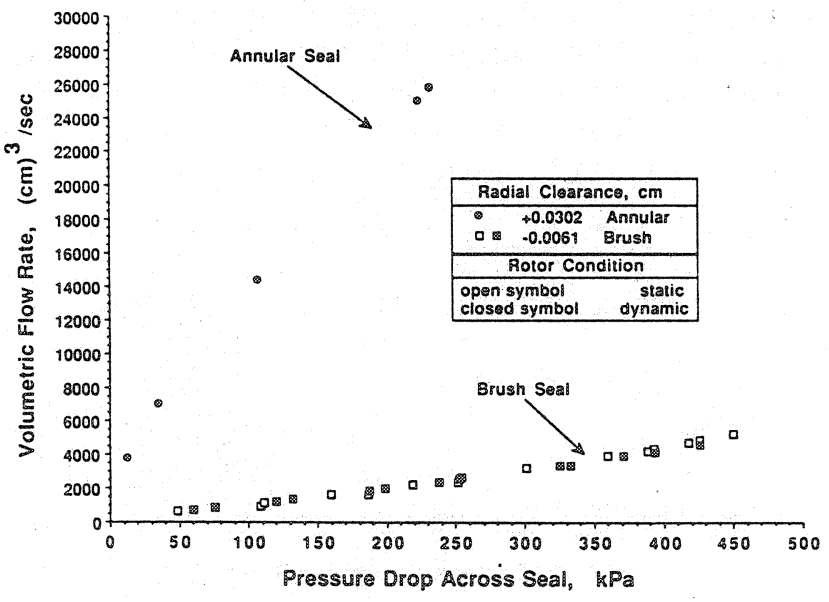

(a) Volumetric flow rate versus pressure drop with Helium as the working fluid for an annular seal and a brush seal.

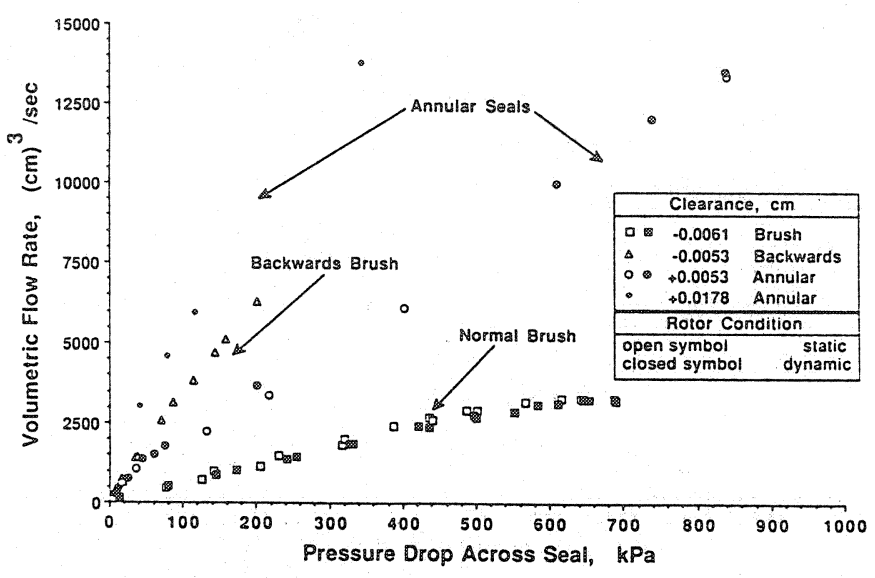

(b) Volumetric flow rate versus pressure drop with air as the working fluid for an annular seal, a reversed brush seal, and a brush seal.

Figure 5.- Comparison of an annular seal and a reversed brush seal leakage with that of a brush seal.

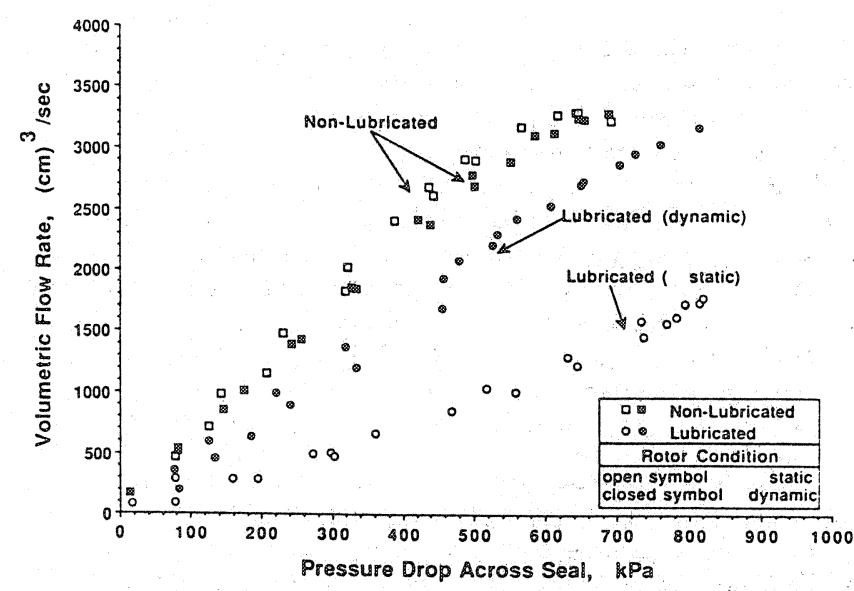

Figure 6. - Effect of lubrication on brush seals with air as the working fluid at a bristle/rotor radial interference of $+0.0061 \mathrm{~cm}$ $(+0.0024$ in. $)$.

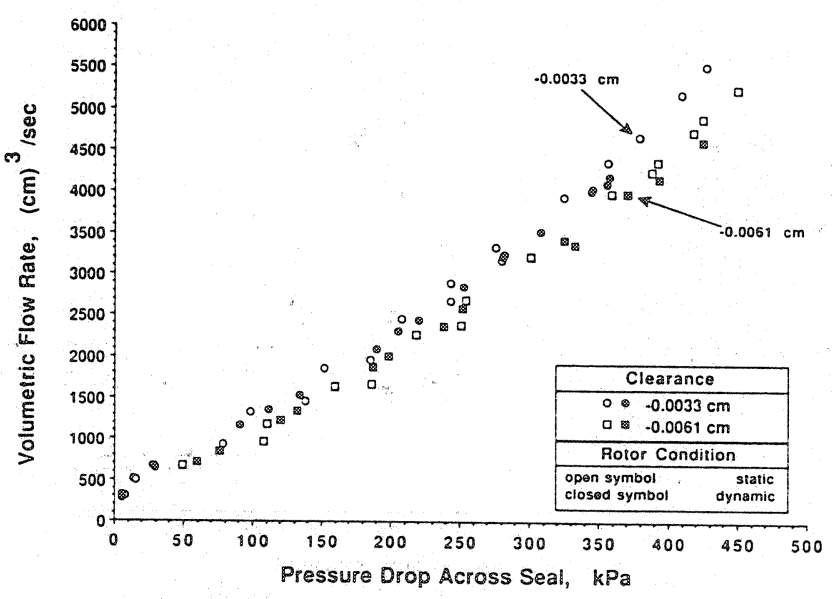

(a) Volumetric flow rate versus pressure drop across the seal with Helium as the working fluid.

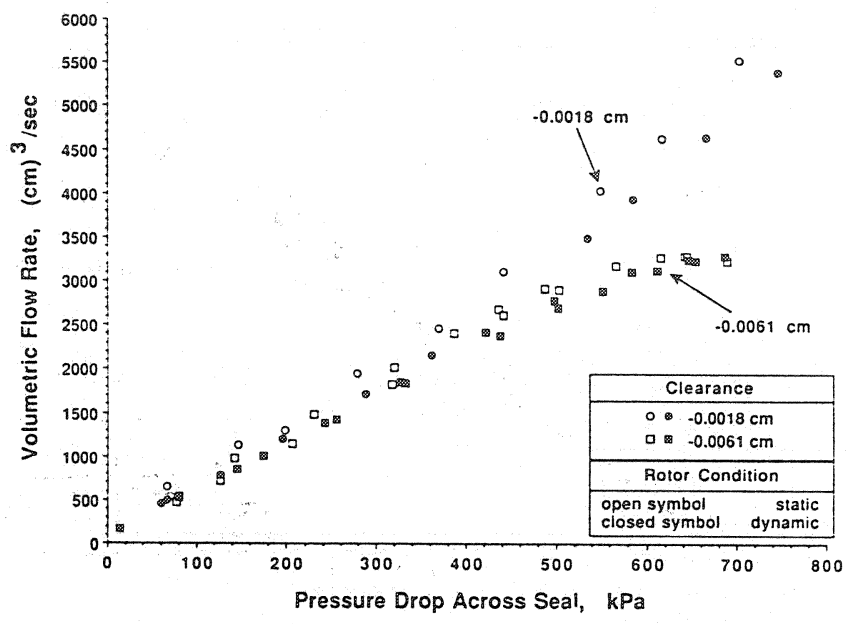

(b) Volumetric flow rate versus pressure drop across the seal with Air as the working fluid.

Figure 7.-Effect of Bristle/Rotor interference on brush seal leakage.

A study of the bristle/rotor interface dynamics was made using high speed film. Results show that as the pressure drop across the seal increased, the bristle pack would split at certain places along the circumference creating holes for a leak path. As the pressure drop decreased the bristle pack closed. Similar observations have been noted for a linear brush seal configuration ("rivering" effect) (Braun, et. al., 1990).

\section{SUMMARY OF RESULTS}

The leakage performance of a brush seal with gaseous air, helium, and carbon dioxide for the test fluids was investigated for several bristle/rotor interferences at static and low rotor speeds. In addition, the effects of packing a lubricant into the bristles and of reversing the pressure drop across the seal were investigated. An annular seal was tested for comparison purposes. In order to generalize the results, they were correlated using corresponding state theory. A brush seal with an inside diameter of $3.792 \mathrm{~cm}$ (1.4930 in.) and a fence height of $0.635 \mathrm{~cm}(0.025 \mathrm{in}$.) was used. The following results were determined: 
1. The air and carbon dioxide data showed a slight improved leakage rate at the rotating over the static condition. Hysteresis effects were negligible.

2. It was found that the air and carbon dioxide data had a flow coefficient equal to 0.0169 and 0.0155 for the static and dynamic shaft conditions, respectively. This was based on a $\mathbb{P}_{\mathrm{r}}=\mathrm{P}_{\text {in }} / \mathbb{P}_{c}$ The helium data did not follow the same trend.

3. A slight improvement in correlating the helium data with that of the air and carbon dioxide was seen if $P_{r}=\Delta P / P_{c}$ is used instead of $P_{r}=P_{i n} / P_{c}$. The cause for the helium data behavior requires further investigation.

4. The brush seal leakage was between 3.5 and 9.5 times less than that of the annular seal showing that the bristles make an effective seal.

5. The lubricated brush seal's leakage rate was up to 2.5 times less than that of the nonlubricated brush seal indicating that the lubricant served to hold the bristles in place and block the porosity through the seal making a more effective seal.

6. For the lubricated seals, the static case showed a greater reduction in leakage than the rotating case. This is the result of the lubricant acting as a seal at the bristle/rotor interface for the static condition.

\section{REFERENCES}

Braun, M.J., Hendricks, R.C., and Canacci, V.A., 1990, "Nonintrusive Qualitative and Quantitative Flow Characterization and Bulk Flow Model for Brush Seals," Presented at the Japan International Tribology Conference, Nagoya.

Childs, D., 1990, "Brush Seal Rotordynamic Damping Charateristics," AIAA Paper 90-2139.

Chupp, R.E., Holle, G.F., and Dowler, C.A., "Simple Leakage Flow Model For Brush Seals," AIAA Paper 91-1913.

Ferguson, J.G., 1988, "Brushes as High Performance Gas Turbine Seals," ASME Paper 88-GT-182.

Flower, R., 1990, "Brush Seal Development System," AIAA Paper 90-2143.

Gorelov, G.M., Reznik, V.E., and Tsibizov, V.I., 1988, "An Experimental Study of the Rate Characteristics of Brush Seals in Comparison with Labyrinth Seals," Aviatsionnaia Tekhnika, No. 4, pp. $43-46$ (in Russian).

Gunn, R.D., Chueh, P.L., and Prausnitz, J.M., 1966, "Prediction of Thermodynamic Properties of Dense Gas Mixtures Containing One or More of the Quantum Gases" AICHE Journal, Vol. 12, pp. 937941.
Hendricks, R.C., Baron, A.K., and Peller, I.C., 1975, "GASP - A Computer Code for Calculating the Thermodynamic and Transport Properties for Ten Fluids: Parahydrogen, Helium, Neon, Methane, Nitrogen, Carbon Monoxide, Oxygen, Fluorine, Argon, and Carbon Dioxide," NASA TN D-7808.

Hendricks, R.C., Braun, M.J., and Mullen, R.L., 1990, "Brush Seal Configurations for Cryogenic and Hot Gas Applications," Advanced Earth-to-Orbit Propulsion Technology, 1990, R.J. Richmond and S.T. Wu, eds., Vol. 2, NASA CP-3092-VOL-2, pp. 78-90.

Hendricks, R.C., et al., 1991, "Some Preliminary Results of Brush Seal/Rotor Interference Effects on Leakage at Zero and Low RPM Using a Tapered-Plug Rotor," AIAA Paper 91-3390. (Also, NASA TM-104396.)

Hendricks, R.C., et al., 1991, "A Bulk Flow Model of a Brush Seal System," Presented at the ASME Turbo Expo - Land, Sea, and Air, 36th ASME International Gas Turbine and Aeroengine Congress and Exposition, Orlando, FL.

Hendricks, R.C., and Sengers, J.V., 1980, "Application of the Principle of Similarity to Fluid Mechanics- -Water and Steam: Their Properties and Current Industrial Applications," 9th International Conference on the Properties of Steam, J. Straub and K. Scheffler, eds., Pergamon Press, Oxford. (Unabridged version as NASA TM-79258, 1979).

Hendricks, R.C., and Simoneau, R.J., 1973, "Application of the Principle of Corresponding States to Two-Phase Choked Flow," NASA TM X-68193.

McCarty, R.D., 1977, "A Comparison of Mathematical Models for the Prediction of LNG Densities," NBS IR 77-867.

Mollerup, J., 1978, "Thermodynamic Properties from Corresponding States Theory," Proceedings of the American Institute of Chemical Engineers 71st Annual Meeting, Miami Beach, FL., American Institute of Chemical Engineers, New York, Paper 45 G.

Schlumberger, J.A., Proctor, M.P., and Hendricks, R.C., 1991, "Eccentricity Effects on Leakage of a Brush Seal at Low Speeds," Presented as the Winter Annual Meeting of the American Society of Mechanical Engineers, Atlanta. (Also, NASA TM-105141).

Simoneau, R.J., and Hendricks, R.C., 1977, "Generalized Charts for Computation of Two-Phase Choked Flow of Simple Cryogenic Liquids” Cryogenics, Vol. 17, pp. 73-76. 
Public reporting burden for this collection of information is estimated to average 1 hour per response, including the time for reviewing instructions, searching existing data sources, gathering and maintaining the data needed, and completing and reviewing the collection of information. Send comments regarding this burden estimate or any other aspect of this collection of information, including suggestions for reducing this burden, to Washington Headquarters Services, Directorate for Information Operations and Reports, 1215 Jefferson Davis Highway, Suite 1204, Arlington, VA 22202-4302, and to the Office of Management and Budget, Paperwork Reduction Project (0704-0188), Washington, DC 20503.

\begin{tabular}{|l|l|r|}
\hline 1. AGENCY USE ONLY (Leave blank) & $\begin{array}{c}\text { 2. REPORT DATE } \\
\text { June } 1992\end{array}$ & $\begin{array}{r}\text { 3. REPORT TYPE AND DATES COVERED } \\
\text { Technical Memorandur }\end{array}$
\end{tabular}

\section{TITLE AND SUBTITLE}

5. FUNDING NUMBERS

Brush Seal Leakage Performance With Gaseous Working Fluids at Static and

Low Rotor Speed Conditions

6. AUTHOR(S)

Julie A. Carlile, Robert C. Hendricks, and Dennis A. Yoder

WU-506-42-72

7. PERFORMING ORGANIZATION NAME(S) AND ADDRESS(ES)

National Aeronautics and Space Administration

Lewis Research Center

Cleveland, Ohio 44135-3191

8. PERFORMING ORGANIZATION

REPORT NUMBER

E-6796

9. SPONSORING/MONITORING AGENCY NAME(S) AND ADDRESS(ES)

National Aeronautics and Space Administration

Washington, DC 20546-0001

10. SPONSORING/MONITORING

AGENCY REPORT NUMBER

NASA TM-105400

\section{SUPPLEMENTARY NOTES}

Prepared for the 37th International Gas Turbine and Aeroengine Congress and Exposition sponsored by the American Institute of Mechanical Engineers, Cologne, Germany, June 1-4, 1992. Responsible person, Julie A. Carlile,

216-977-7431.

12a. DISTRIBUTION/AVAILABILITY STATEMENT

12b. DISTRIBUTION CODE

Unclassified - Unlimited

Subject Category: 34

Available electronically at http://gltrs.grc.nasa.gov

This publication is available from the NASA Center for AeroSpace Information, 301-621-0390.

13. ABSTRACT (Maximum 200 words)

The leakage performance of a brush seal with gaseous working fluids at static and low rotor speed conditions was investigated. This report includes the leakage results for air, helium, and carbon dioxide at several bristle/rotor interferences. In addition, the effects of packing a lubricant into the bristles and also of reversing the pressure drop across the seal were investigated. Results were compared to that of an annular seal at similar operating conditions. In order to generalize the results, they were correlated using corresponding state theory. The brush seal tested had a bore diameter of $3.792 \mathrm{~cm}$ ( $1.4930 \mathrm{in}$.), a fence height of $0.0635 \mathrm{~cm}(0.025 \mathrm{in}$.), and 1800 bristles/cm-circumference ( $4500 \mathrm{bristles} /$ in.-circumference). Various bristle/rotor radial interferences were achieved by using a tapered rotor. The brush seal reduced the leakage in comparison to the annular seal, up to 9.5 times. Reversing the pressure drop across the brush seal produced leakage rates approximately the same as that of the annular seal. Addition of a lubricant reduced the leakage by 2.5 times. The air and carbon dioxide data were successfully correlated using corresponding state theory. However, the helium data followed a different curve than the air and carbon dioxide data.

\section{SUBJECT TERMS}

Brush; Seals; Leakage; Helium; Air; Carbon dioxide

17. SECURITY CLASSIFICATION OF REPORT

Unclassified

\section{SECURITY CLASSIFICATION OF THIS PAGE \\ Unclassified}

19. SECURITY CLASSIFICATION OF ABSTRACT

Unclassified
15. NUMBER OF PAGES

8

16. PRICE CODE

$\mathrm{A} 02$

20. LIMITATION OF ABSTRACT

Standard Form 298 (Rev. 2-89)

Prescribed by ANSI Std. Z39-18 298-102 